انتقال زن fld سيانوباكتريايى به كَياه برنج به روش اترو باكتريوم

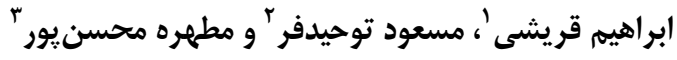

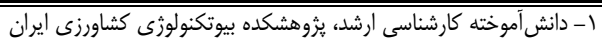

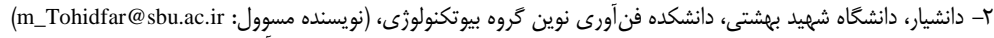

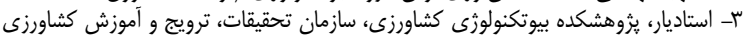

ت تاريخ دريافت:

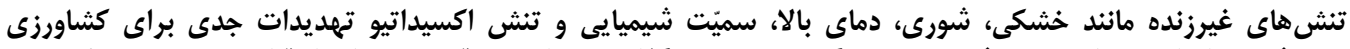

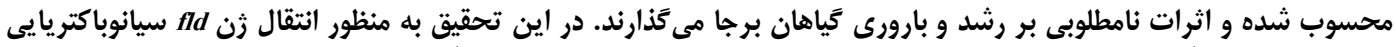

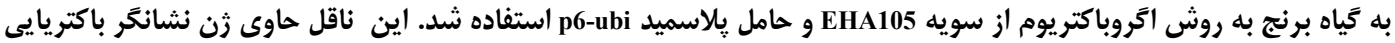

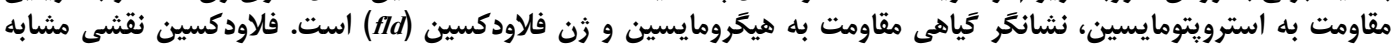

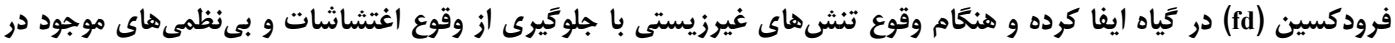

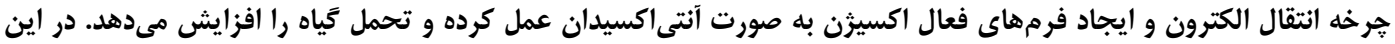

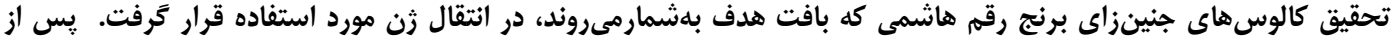

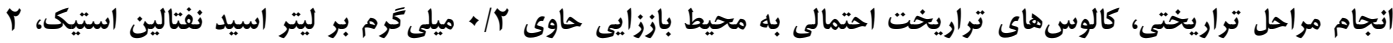

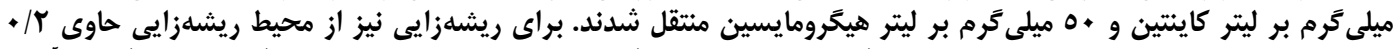

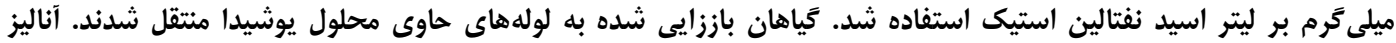

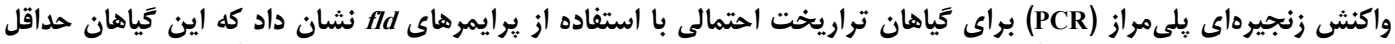

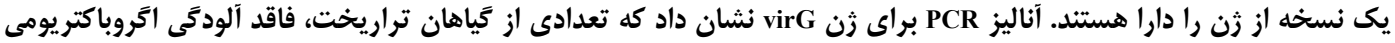

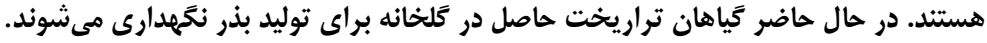

وازههاى كليدى: اتروباكتر يوم، برنج تراريخت، تنش هاى غيرزنده، فلاودكسين

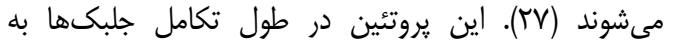

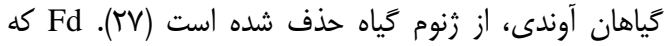

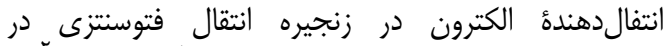

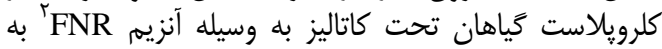

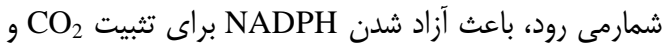

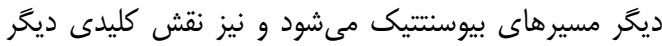

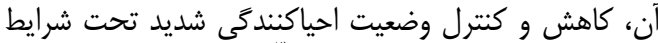

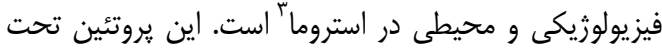

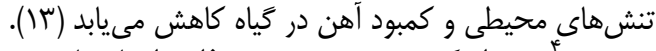

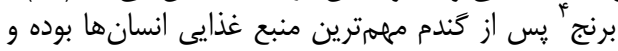

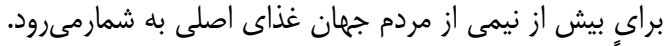

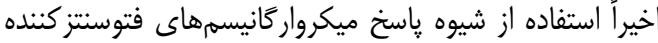

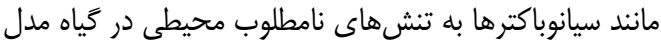

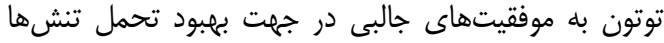

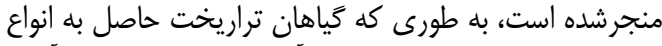

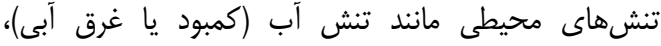

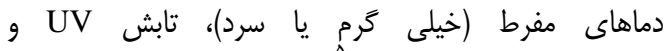

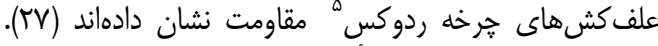

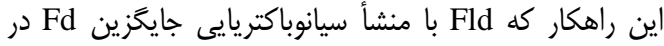

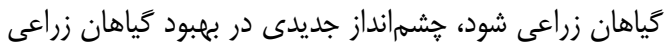

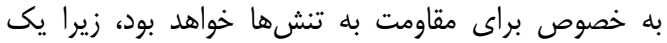

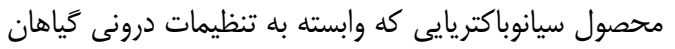

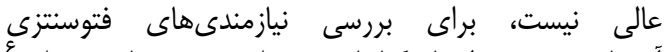

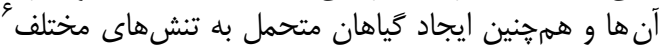

در كشاورزى مهمترين عامل كاهش عملكرد، تنشهاى

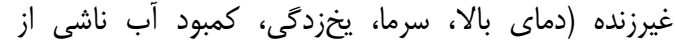

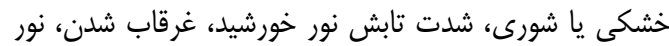

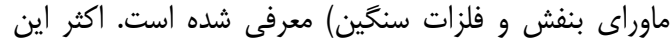

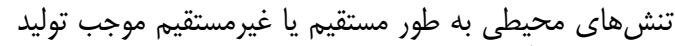

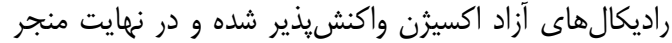

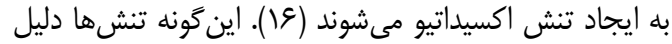

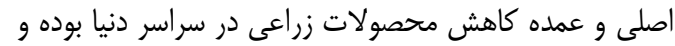

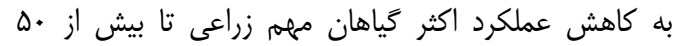

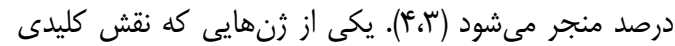

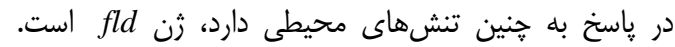

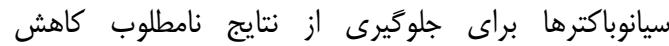

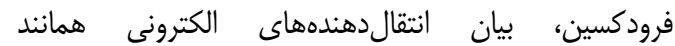

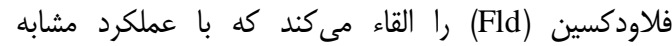

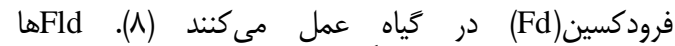

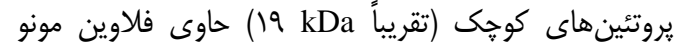

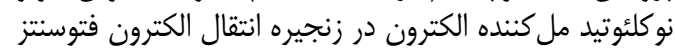

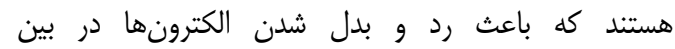

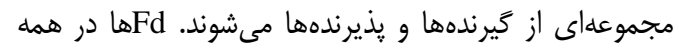

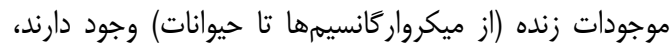

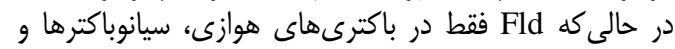

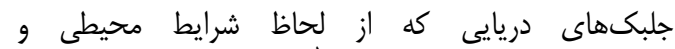
تغذيهاى در محيطهاى حاد' زيست ميكى كنند، يافت 
كالوسزايى و توليد كالوس جنينزا در رقم مورد مطالعه،

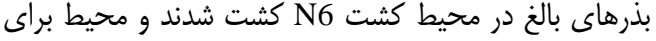

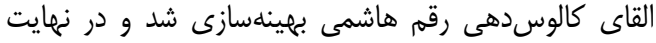

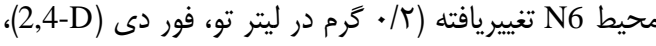

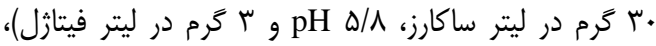

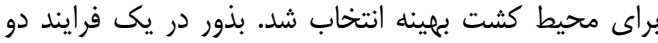

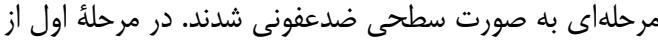

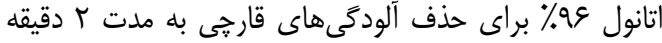

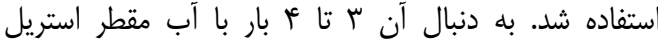

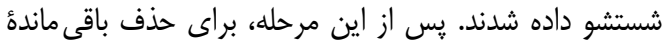

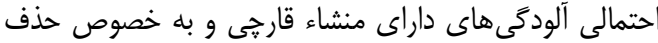

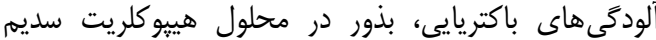

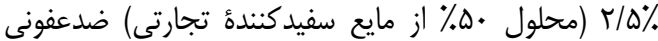

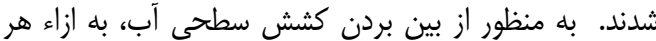

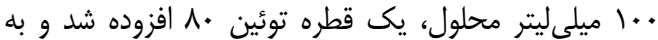

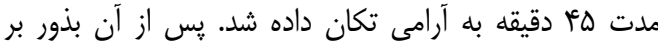
روى كاغذ صافى خشك شدند.

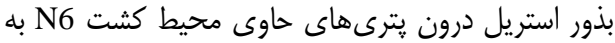

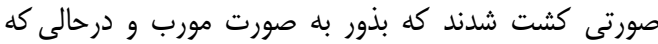

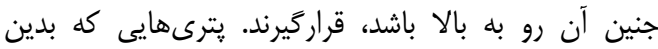

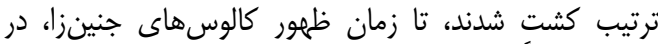

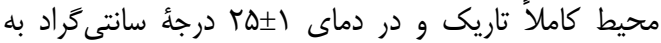

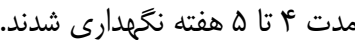

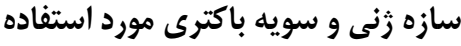

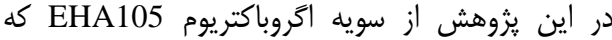

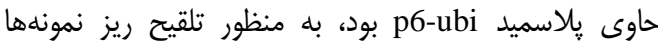

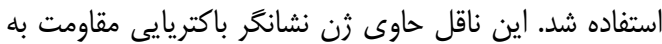

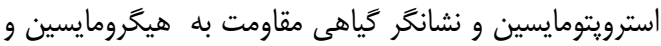
زن فلاودكسين (fld) تحت ييشبر ubiquitin است (شكل (1) ).
موثر خواهد بود. طبق كزارش توكنتى و همكاران (سٓ بار) بيان

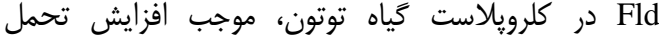

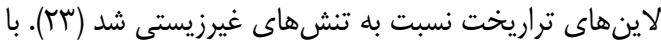

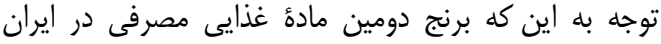

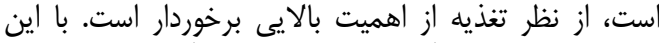

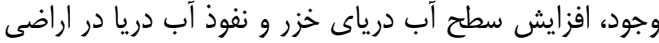

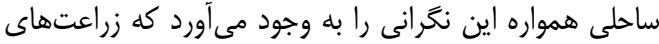

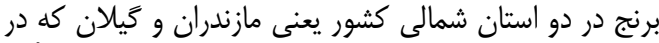

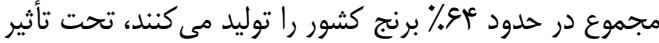

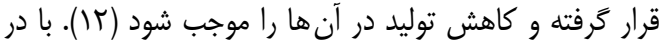

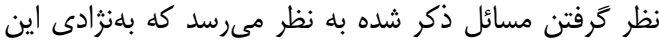

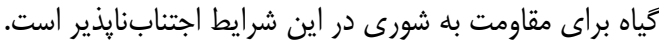

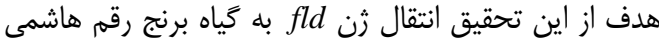

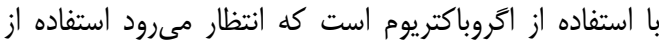

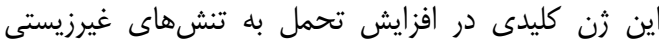
نقش بلهز ايى را ايفا كند.

\section{مواد و روشها}

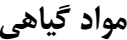

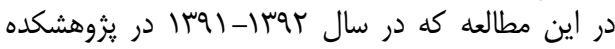

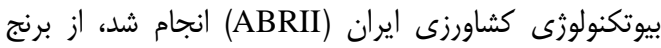

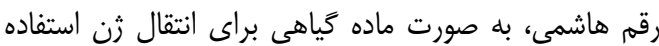

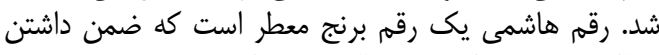

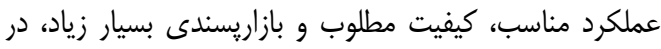

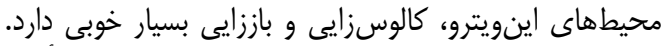
بذور مورد نياز از مؤسسه تحقيقات برنج كشور در رشت بازئ بأمين

كثت بافت و به دست آوردن كالوس جنينزا در اين تحقيق به منظور انجام بررسى روى وضنين وضعيت

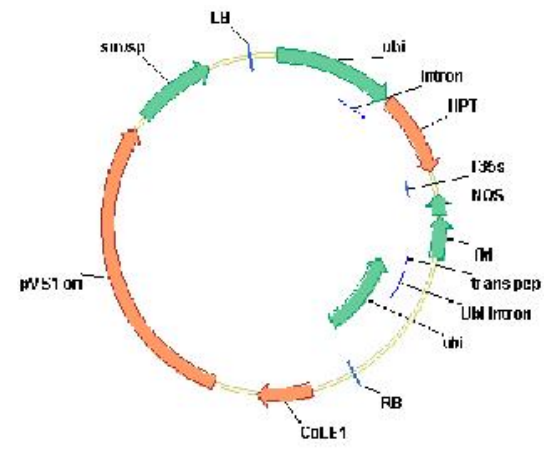

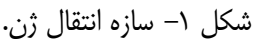

Figure 1. Physical map of recombinant pBI121 containing target genes

كلونىهاى اگروباكتريومى كه روى محيط LB انتخابى رشد كرده بودند، واكنش كلونى اختصاصى ثن fld انجام شد.
انتقال يلاسميد به آَروباكتريوم و انجام كلونى PCR

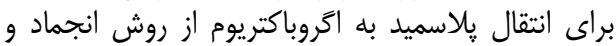

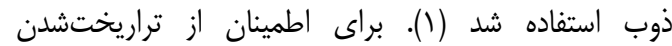




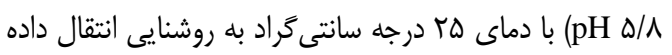

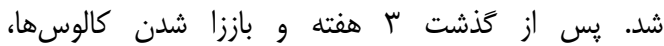

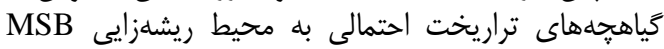

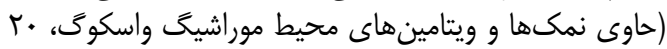

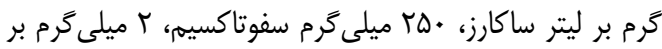

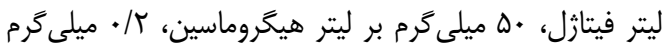

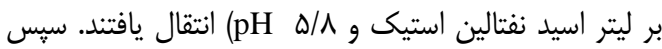

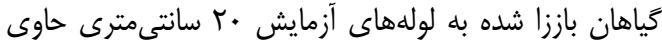
محلول يوشيدا منتقل شدند.

\section{استخراج DNA زنومى و آناليز مولكولى منيلى}

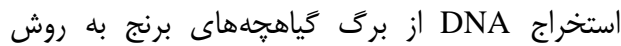
دلايورتا انجام گرفت (V) PCR DNA ra) $\mathrm{MgCl} 2$ dNTP

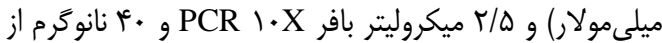

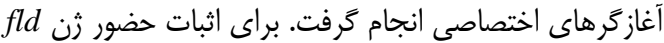

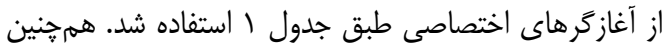

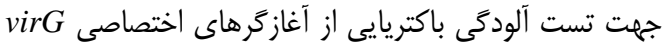

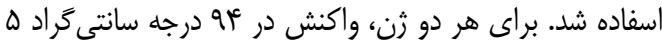

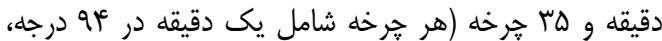

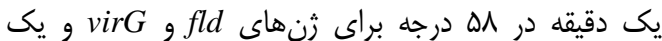
دقيقه در VT درجه سانتى

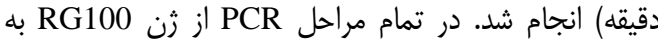

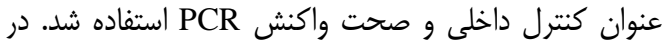
هر سه واكنش از نمونه آب (فاقد هر كونه دئه

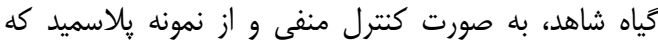

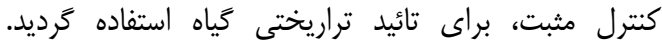

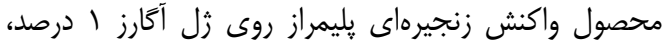

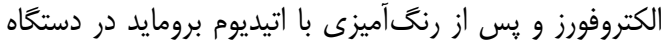
زل داك عكسبردارى گرديد.

نتايج و بحث تائيد انتقال ثن و دن

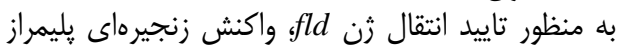
(PCR)

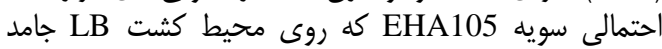
انتخابى حاوى آنتىبيوتيك استريتومايسين، اسيكتينومايسين و

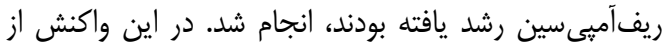

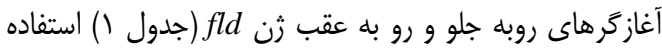

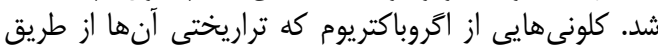

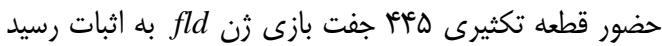

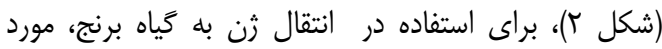

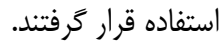

رشد آكَروباكتريوم

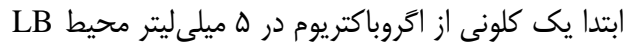

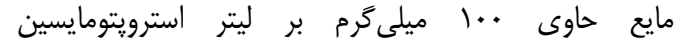

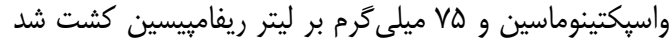
و در دماى \ T درجه سانتى

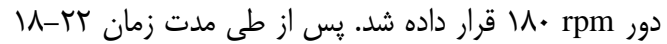

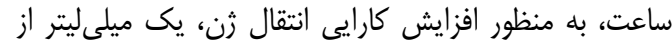

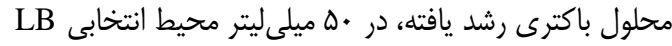

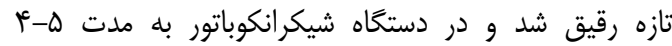

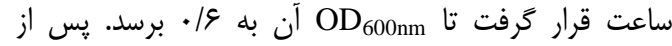

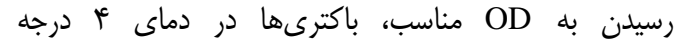
سانتى

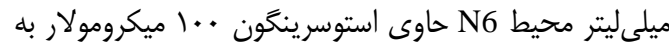

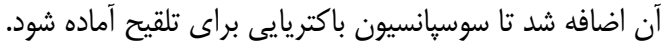

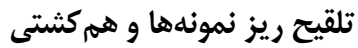

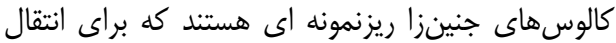

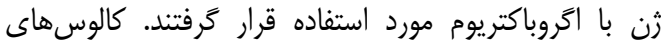

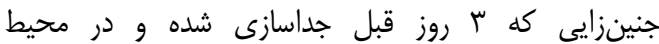

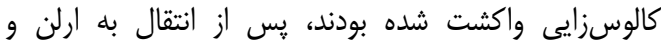

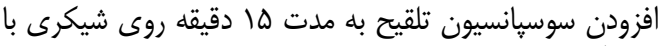

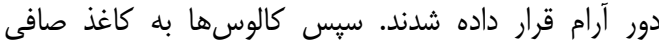

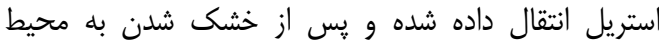

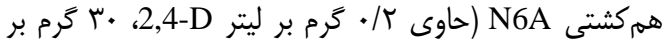

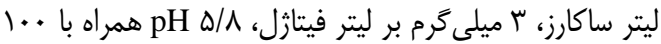

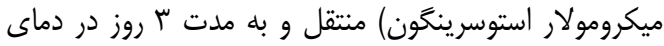

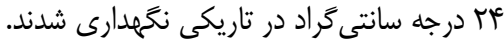

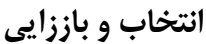

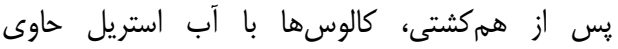

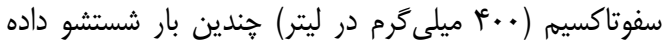

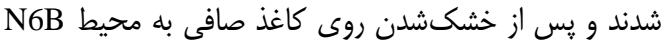

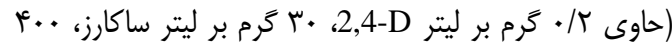

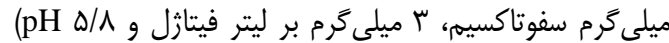

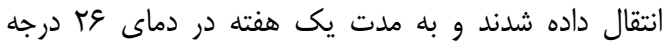
سانتى

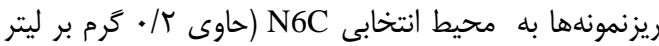
2,4-D

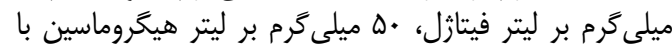

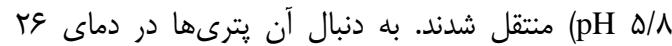

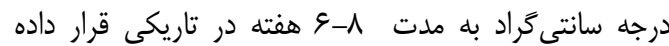

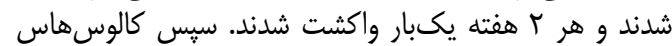

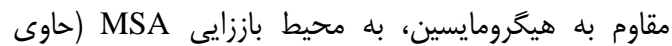

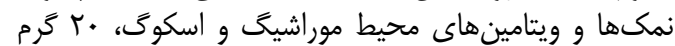

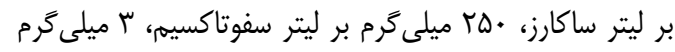

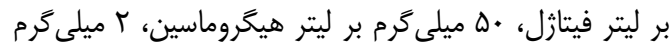

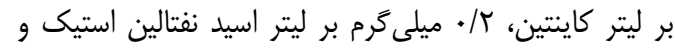


1. انتقال ثن fld سيانوباكتريايى به كياه برنج به روش اخرو باكتريوم

Table 1. Used primers for PCR of putative transgenic plant

$$
\text { جدول ا- آغازكرهاى مورد استفاده در آناليز PCR كياهان تراريخت احتمالى }
$$

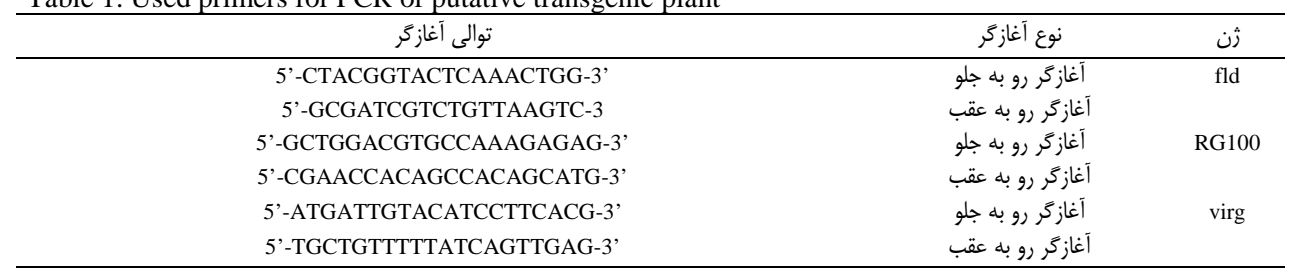

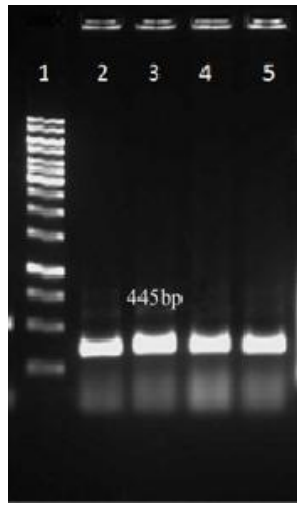

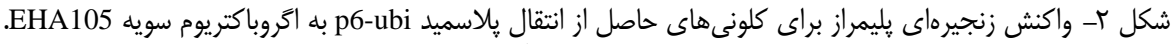

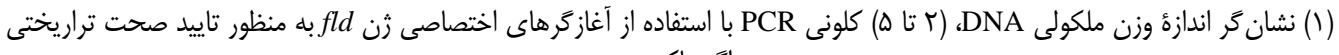

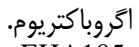

Figure 2. Polymerase change reaction for recombinant EHA105 containing p6-ubi. 1) Molecular Size Marker, 2) 2-5 Colony PCR for fld gene using specific primer

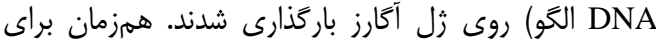

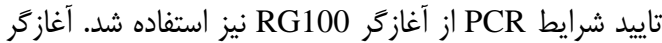

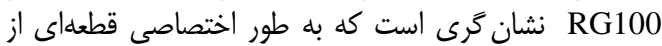

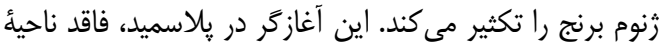

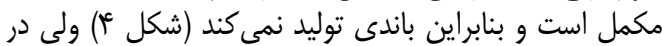

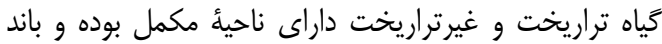

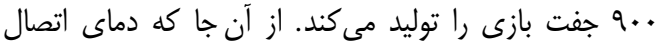

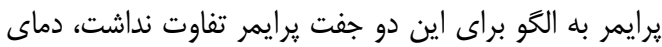

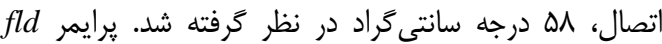

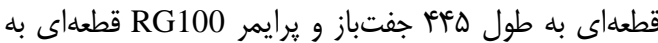

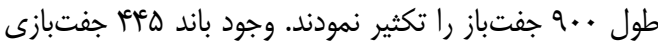

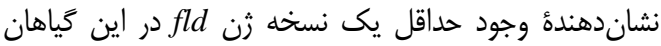

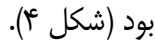

توليد كَاهان تراريخت و آناليز آنها

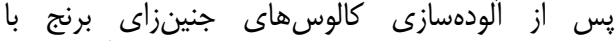

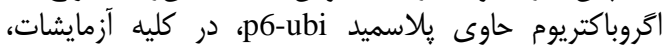

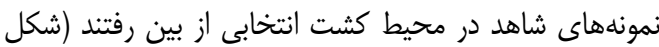

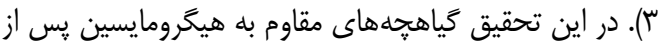

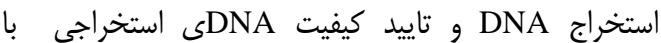

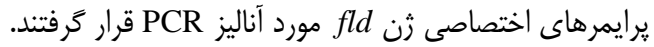

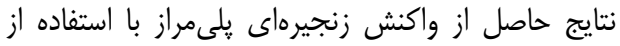

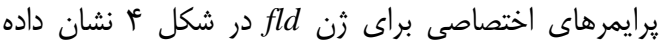

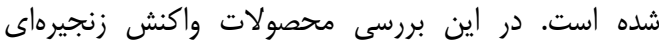

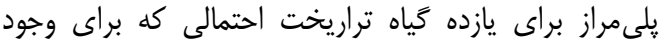

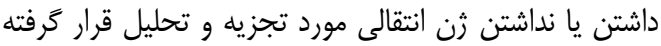

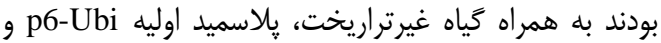
نيز كنترل منفى شامل آب (داراى كلئه مواد مورد نياز به جز اليه 

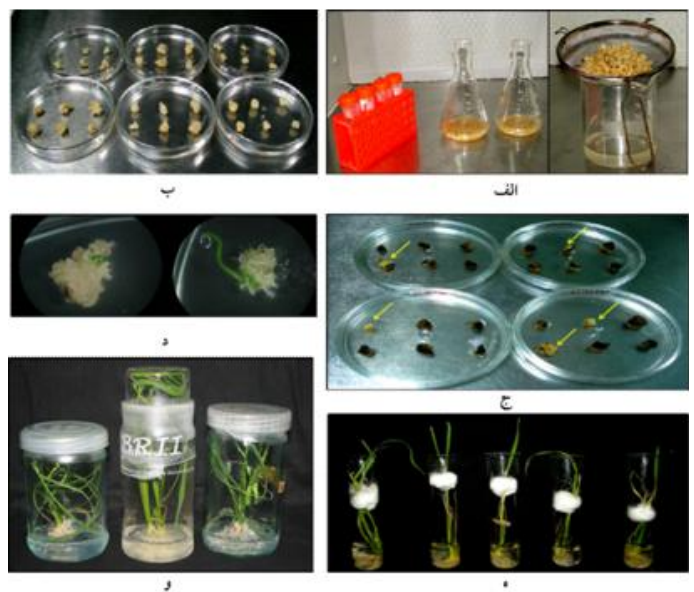

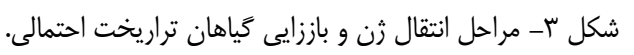

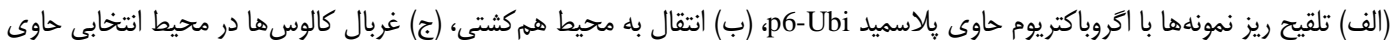

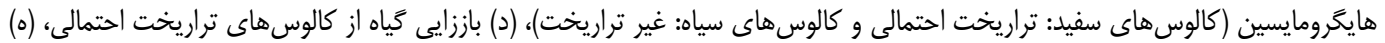

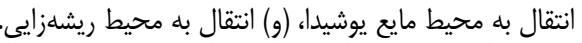

Figure 3. Stpes of gene transformation and regeneration of putative transgenic plants.a) Inoculation of explants using Agrobacterium containing p6u-Ubi.b) Transfer to co-culture medium, c) Screening of calli in selective medium (White callus: putative transgenic and Black callus: Non-transgenic), d) Regeneration of putative transgenic calli, e) Transfer to yoshida medium, f) Rooting medium

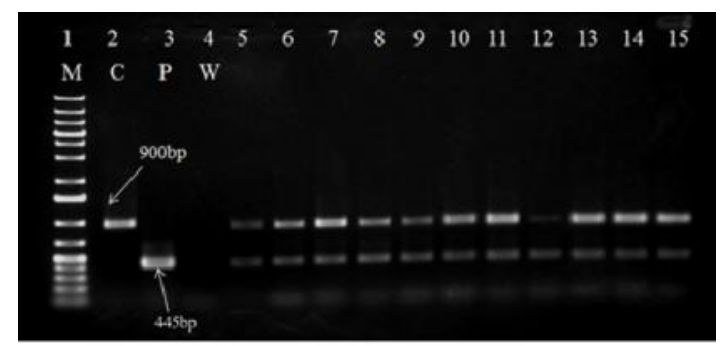

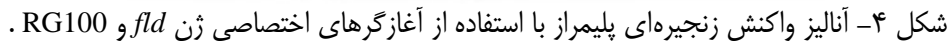

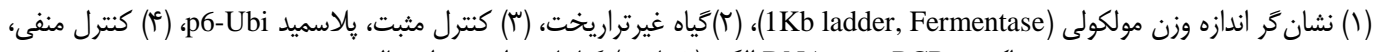

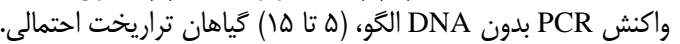

Figure 4. Polymerase change reaction for RG100 and fld genes using specific primers. 1) Molecular Size marker, 2) Non-transgenic plant,3) Positive control, 4) Negative control, 5-15) Putative transgenic plants.

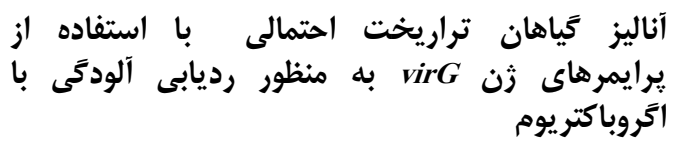

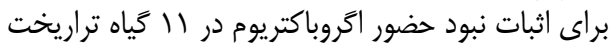

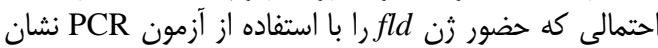

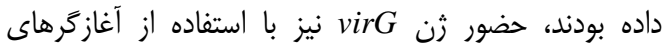

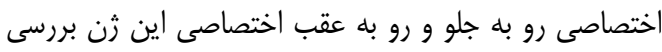

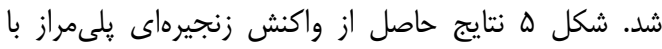

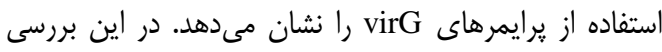

مطابق شكل \& نبودن باند در كنترل منفى يا واكنش

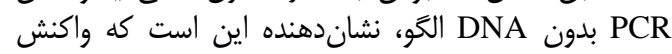

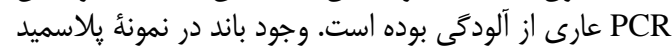

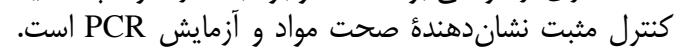

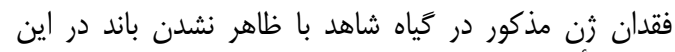

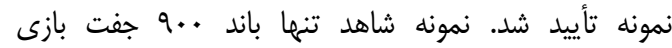

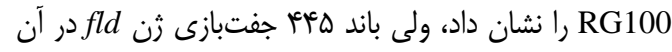

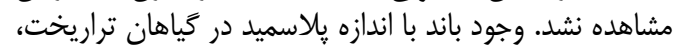

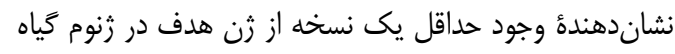


نشاندهنده حضور اكروباكتريوم در نمونهها بوده و د در نمونههايى كه PCR زن

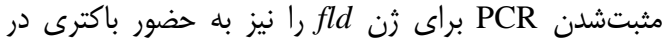

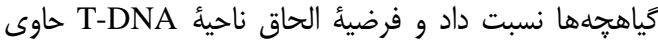

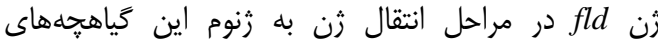

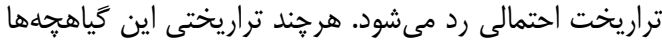

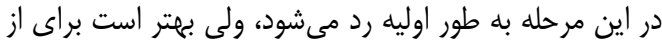

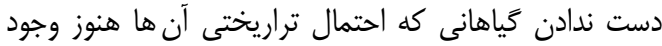

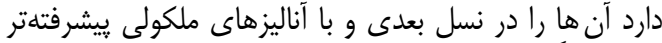

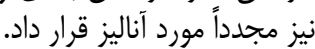

محصولات واكنش زنجيرهاى يلىمراز براى يازده كياه

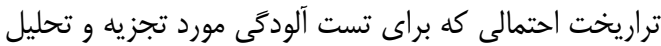

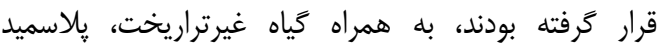

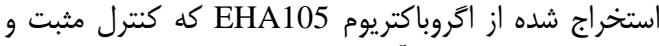

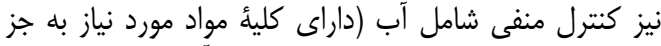

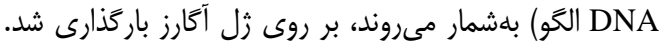

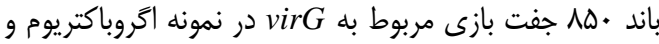

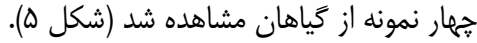

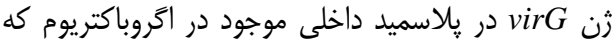
فاقد ناحيأ T-DNA است قرار دارد و بنابراين حضور آن

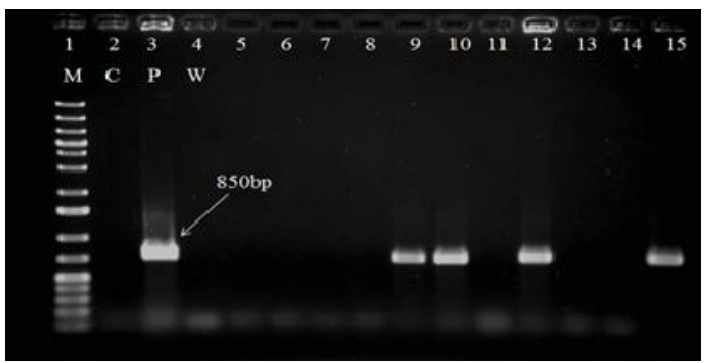

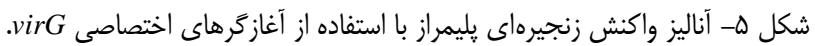

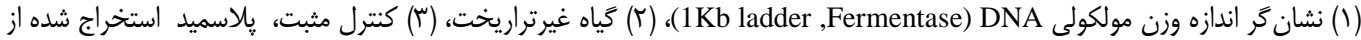

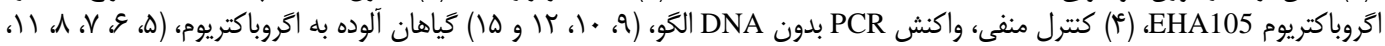

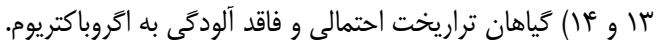

Figure 5. Polymerase change reaction for virG gene using specific primers. 1) Molecular Size marker, 2) Nontransgenic plant,3) Positive control, 4) Negative control, 9,10,12 and 15) Putative transgenic plants which were contaminated with Agrobacterium, 5,6,7,8,11,13 and 14) Putative transgenic plants without Agrobacterium contamination.

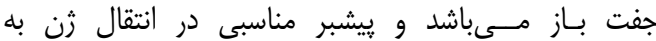

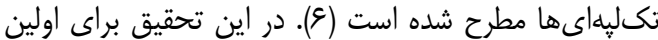

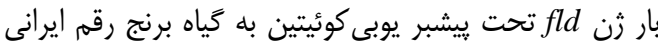

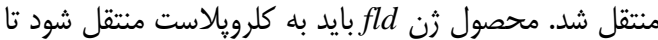

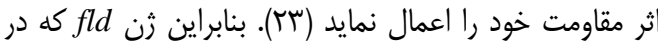

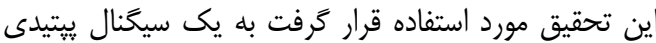

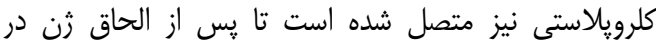

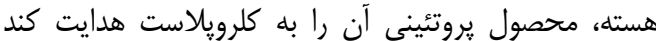

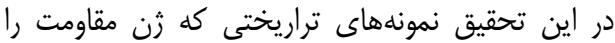

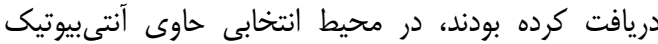

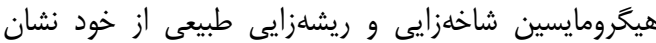

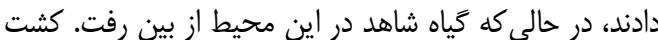

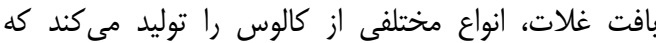

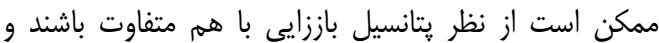

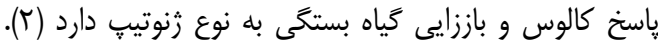

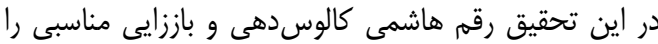

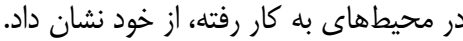

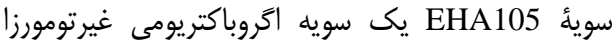
است كه از سويه A281 اشتقاق يافته است و ناقلى مناسئ مناسب

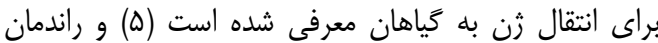

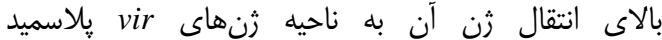

ييشبر 35S يك ييشبر دائمى بسيار قوى است و به طور

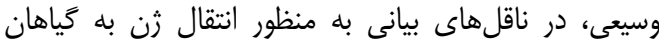

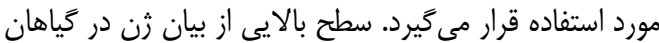

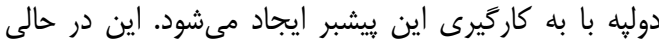

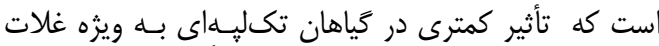

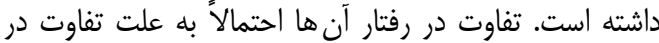

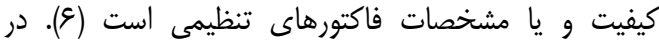

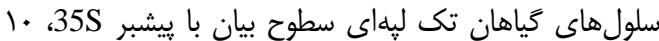

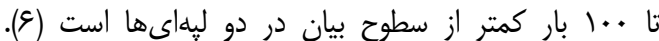

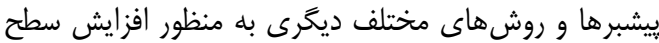

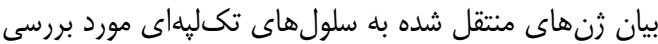

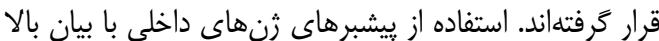

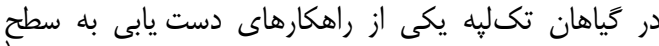

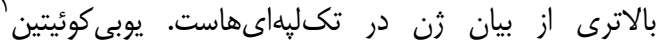

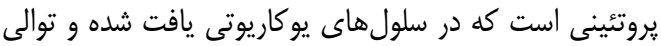

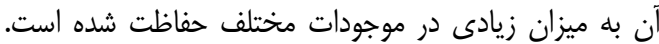

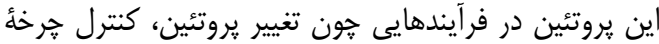

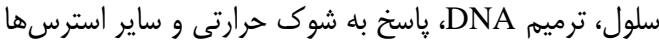

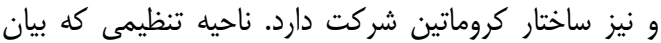

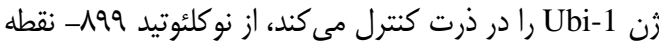

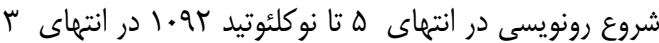

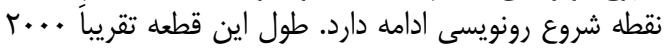


ايجاد صفت تحمل به شورى و خشكى در گياهان هميشه

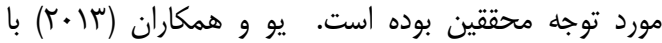

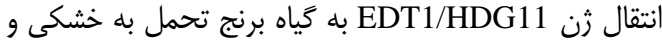

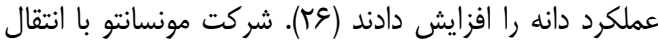

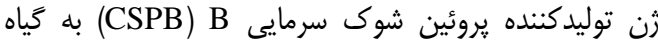
ذرت، گياه تراريخت

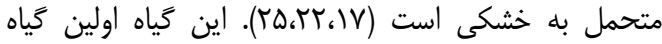

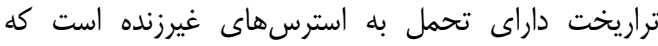
تجارى سازى شده است. در اين تحقيق V Vياه يس إز مراحل انتقال ثن حاصل

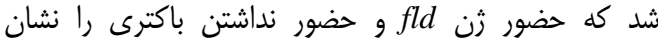

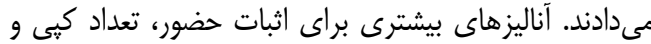

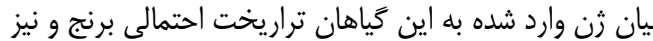

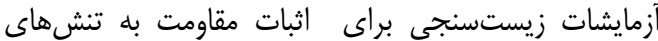

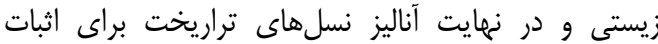

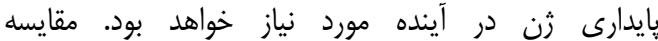

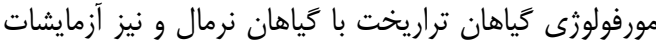

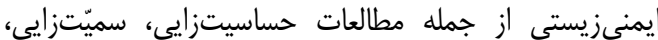

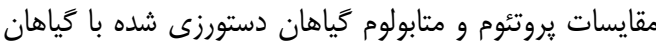

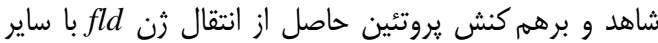

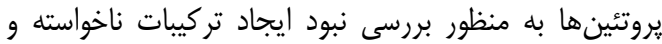

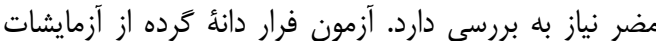

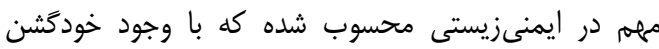

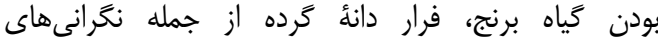

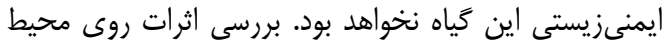

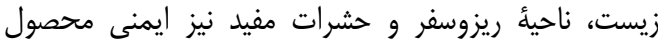

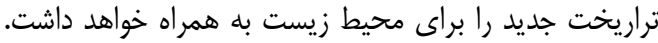

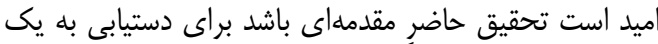

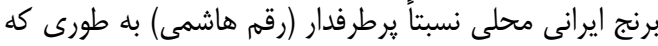

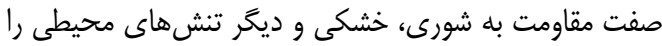
نيز به همراه داشته باشد.

$$
\text { تشكر و قدردانى }
$$

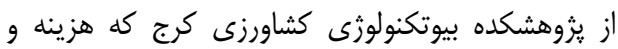

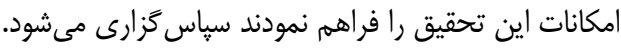

(pTiBo542) Ti

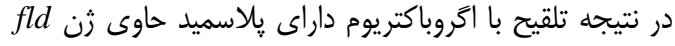

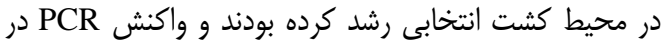

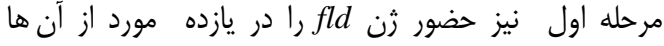

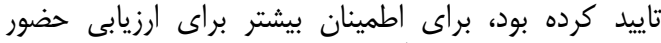

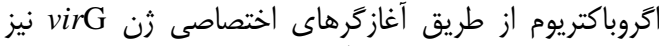

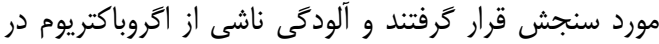

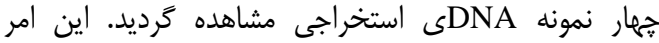

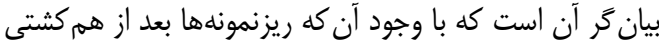

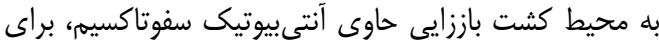

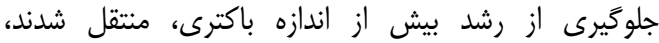

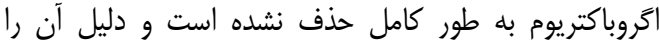

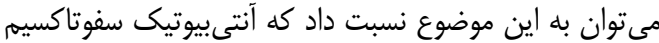

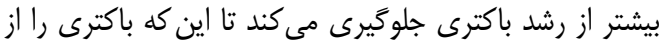
بين ببرد (19).

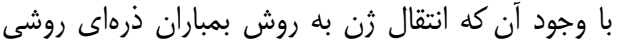

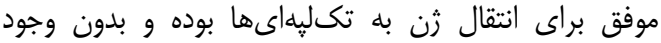

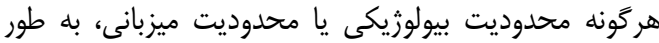

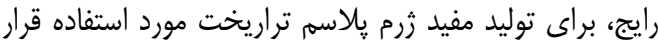

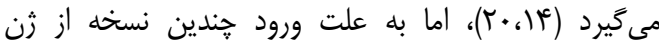

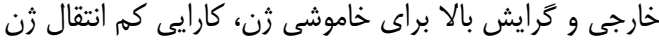

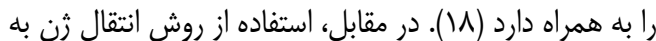

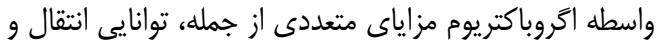

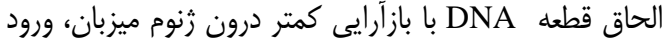

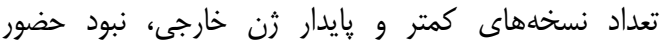

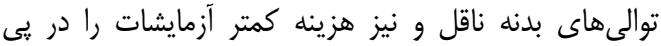

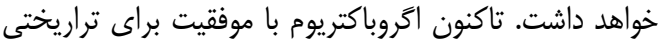

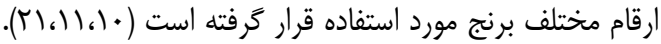

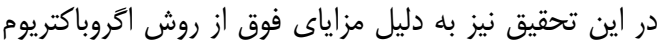

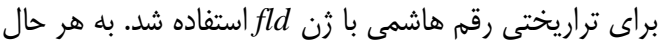

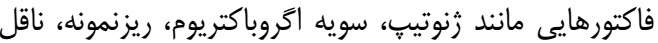

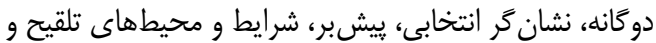

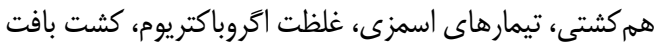

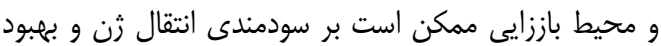

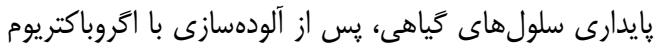

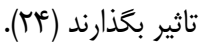


1. An, G. B.D. Wastson and C.C. Chiang 1986. Transformation of tobacco, tomato, potato and Arabidopsis thaliana using a binary Ti vector system. Plant Physiology, 81: 301-305.

2. Baskaran, P., B.R. Rajeswari and N. Jayabalan. 2005. A simple approach to improve plant regeneration from callus culture of Sorghum bicolor (L.) Moench for crop improvement. Journal of Agricultural Technology, 1: 179-192.

3. Boyer, J.S. 1982. Plant productivity and environment. Science, 218: 443-448.

4. Bray, E.A., J. Bailey-serres and E. Weretilnyk. 2000. Responses to abiotic stresses. Biochemistry and Molecular Biology of Plants. American Society of Plant Physiologists, Rockville, MD, USA 11581249.

5. Cervera, M., M. Lopez, M. Navarro and L. Pena 1998b. Virulence and supervirulence of Agrobacterium tumefaciens in woody fruit plants. Physiological and Molecular Plant Pathology, 52: 67-78.

6. Christensen, A.H. and P.H. Quail. 1996. Ubiquitin promoter-based vectors for high-level expression of selectable and/or screenable marker genes in monocotyledonous plants. Transgenic Research, 5: 213-218.

7. Dellaporta, S.L., J. Wood and J.B. Hicks 1983. A plant DNA mini preparation, version II. Plant Molcular Biology Report, 1: 19-21.

8. Falk, S., G. Samson, D. Bruce, N.P.A. Huner and D.E. Laudenbach. 1995. Functional analysis of the iron-stress induced CP 43' polypeptide of PS II in the Cyanobacterium synechococcus sp. PCC 7942. Photosynthesis Research, 45: 51-60.

9. Ghorbel, R., C. Lopez, C. Fagoaga, P. Moreno, L. Navarro, R. Flores and L. Pena. 2001. Transgenic citrus plants expressing the citrus tristeza virus $p 23$ protein exhibit viral like symptoms. Molecular Plant Pathology, 2: 27-36.

10. Hiei, Y., S. Ohta, T. Komari and T. Kumashiro. 1994. Efficient transformation of rice (Oryza sativa L.) mediated by Agrobacterium and sequence analysis of the boundaries of the T-DNA. Plant Journal, 6: 271-282.

11. Ishizaki, T. and T. Kumashiro. 2008. Genetic transformation of NERICA, interspecific hybrid rice between Oryza glaberrima and $\mathrm{O}$, sativa, mediated by Agrobacterium tumefaciens. Plant Cell Report, 27: 319-327.

12. Kavusi, M. 1994. Determine the appropriate model for predicting the performance of different rice varieties under salt Sepeedrud, Hassansaraii and khazar. Dissertation, University of Tbriz, Iran (In Persian).

13. Kramer, D.M., G. Johnson, O. Kiirats and G.E. Edwards. 2004. New fluorescence parameters for the determination of QA redox state and excitation energy fluxes. Photosynth Research, 79: 209-218.

14. Li, D., J. Gao, C. Shen, Z. Fang, Y. Xia, L. Yuan and M. Cao. 2013. Production of Green Fluorescent Protein in Transgenic Rice Seeds. Journal of Nanoscience and Nanotechnology, 13: 2045-2050.

15. Li, Z., S. Jayasankar and D.J. Gray. 2004. Bi-directional duplex promoters with duplicated enhancers significantly increase transgene expression in grape and tobacco. Transgenic Research, 13: 143-154.

16. Mittler, R., S. Vanderauwera, M. Gollery and F. Van Breusegem. 2004. Reactive oxygen gene network of plants. Trends Plant Science, 9: 490-498.

17. Monsanto Company. 2009. Petition for the determination of non-regulated status for MON 87460. www.aphis.usda.gov/biotechnology/not_reg.html (accessed 23 May 2013).

18. Montemurro, C., W. Sabatta, H.H. Stinbiss, A. Soltesz, A. Blanco and C. Crosatti. 2008. Agrobacterium-mediated transformation in durum wheat. Poster Abstract-E.09.

19. Pena, L., M. Cervera, C. Fagoaga, J. Romero, A. Ballester, N. Soler, E. Pons, A. Rodrguez, J. Peris, J. Juarez and L. Navarro. 2010. Compendium of Transgenic Crop Plants, Volume 5: Transgenic Tropical and Subtropical Fruits and Nuts: Citrus fruit.

20. Rakszegi, M., S. Tamas, P. Szucs, L. Tamas and Z. Bedo. 2001. Current status of wheat transformation. Plant Biotechnology, 3: 67-81.

21. Saika1, S., S. Nonaka, K. Osakabe and S. Toki1. 2012. Sequential Monitoring of Transgene Expression Following Agrobacterium-Mediated Transformation of Rice. Plant and Cell Physiology, 53: 1974-1983.

22. Sammons, B., J. Whitsel, L.G. Stork, W. Reeves and M. Horak. 2014. Characterization of droughttolerant maize MON 87460 for use in environmental risk assessment. Crop Science, 54: 719-729.

23. Tognetti, V.B., J.F. Palatnik, M.F. Fillat, M. Melzer, M.R. Hajirezaei, E.M. Valle and N. Carrillo. 2006. Functional replacement of ferredoxin by a Cyanobacterial flavodoxin in tobacco confers BroadRange stress Tolerance. The plant cell, 18: 2035-2050.

24. Tohidfar, M. and M. Mohsenpour. 2010. Effective factors in Cotton (Gossipium spp) Transformation Using Agrobacterium. Journal of Agricultural biotechnology, 2: 1-24 (In Persian).

25. USDA-APHIS. 2011. Final environmental assessment for MON 87460 corn. USDA-APHIS-Animal and Plant Health Inspection Service. www.aphis.usda.gov/biotechnology/not_reg.html (accessed 23 May 2013).

26. Yu, L., X. Chen , Z. Wang, S. Wang, Y. Wang, Q. Zhu, S. Li and C. Xiang. 2013. Arabidopsis enhanced drought tolerance1/homeodomain glabrous11 confers drought tolerance in transgenic rice without yield penalty. Plant Physiology, 162: 1378-1391.

27. Zurbriggen, M., V.B. Tognetti, E.M. Valle and N. Carrillo. 2007. Stress-inducible flavodoxin from photosynthetic microorganisms: The mystery of flavodoxin loss from the plant genome. IUBMB Life, 59: $355-360$. 


\title{
Agrobacterium-Mediated Transformation of Rice using Cyanobacteria fld Gene
}

\author{
Ebrahim Ghoreyshi ${ }^{1}$, Masoud Tohidfar ${ }^{2}$ and Motahhareh Mohsenpour ${ }^{3}$

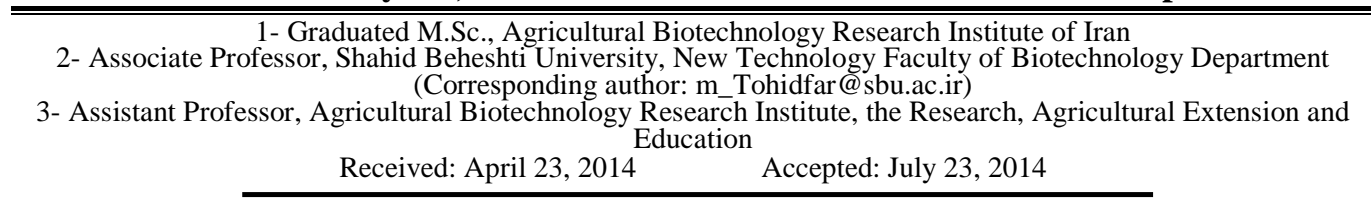

\begin{abstract}
Abiotic stresses such as drought, salt, high temperature, chemical toxicity and oxidative stress are considered serious to agriculture and adversely affect the growth and reproduction of crops. Production of transgenic rice was studied utilizing Agrobacterium-mediated strain EHA105 and p6-ubi vector. This vector contains spectinomycin resistance gene as bacterial selectable marker, hygromycin resistance gene as plant selectable marker and flavodoxin (fld) gene. Flavodoxin has similar role to ferredoxin function and during abiotic stress acts as an antioxidant by preventing conflicts in the electron transport chain and forms reactive oxygen species. In this study embryogenic calli of rice Hashemi cultivar were used for gene transformation. Putative transgenic calli were transferred to regeneration medium containing 0.2 $\mathrm{mgl}^{-1}$ NAA, $2 \mathrm{mgl}^{-1}$ kinitin and $50 \mathrm{mgl}^{-1}$ hygromycin. For rooting $0.2 \mathrm{mgl}^{-1} \mathrm{NAA}$ was used in rooting medium. Regenerated plants were placed in yoshida solution. PCR analysis using fld specific primers showed at least one copy of fld gene in putative transgenic plants genome. The results of PCR related to virG gene confirmed lack of bacterial contamination. Transgenic plants developed during the course of this study are currently being grown in greenhouse for seed production.
\end{abstract}

Keywords: Abiotic stress, Agrobacterium, Flavodoxin, Transgenic rice 